\title{
Regeneração natural em fragmento de Floresta Ombrófila Semidecidual em Sergipe, Brasil ${ }^{1}$
}

\author{
Milton Marques Fernandes ${ }^{2}$; Thalita Rocha Silva ${ }^{3}$; Alexandre Siqueira Pinto ${ }^{4}$; Icaro Bruno Andrade \\ Souza $^{5}$; Márcia Rodrigues de Moura Fernandes ${ }^{6}$
}

Resumo: O trabalho foi realizado com o objetivo de avaliar a florística, fitossociologia e similaridade florística entre o estrato regenerativo de duas áreas de um fragmento de Floresta Ombrófila Semidecidual, em diferentes estágios sucessionais (inicial e avançado), no município de São Cristóvão, SE. Para a avaliação da regeneração natural das espécies arbóreas foram alocadas de forma sistemática 10 parcelas de $10 \mathrm{~m}^{2}(2 \mathrm{~m}$ x $5 \mathrm{~m})$ em cada área. Organizou-se a inventariação de todos os indivíduos regenerantes, em um nível de inclusão menor ou igual a $15 \mathrm{~cm}$. Calcularam-se os parâmetros da estrutura horizontal, diversidade de Shannon, equabilidade de Pielou e similaridade florística entre as áreas estudadas. A floresta em estágio avançado de sucessão tem maior número de espécies, pertencentes ao grupo clímax na sucessão, porém as espécies com maior número de indivíduos são pioneiras nas duas áreas. A menor incidência de luz na regeneração natural da floresta em estágio avançado de sucessão resultou em uma maior densidade de espécies da regeneração. As duas áreas tiveram similaridade florística e de diversidade.

Palavras - chave: Mata Atlântica; Fitossociologia; Sub-bosque.

\section{Natural regeneration in semideciduous ombrophilous forest fragment in Sergipe state, Brazil}

\begin{abstract}
The objective of this study was to evaluate floristic, phytosociology and floristic similarity between the regenerative stratum of two areas of a semideciduous ombrophilous forest fragment, in different successional stages (initial and advanced), in Sergipe state. For the evaluation of the natural regeneration of the tree species, 10 plots of $10 \mathrm{~m}^{2}(2 \mathrm{mx} 5$ $\mathrm{m}$ ) were systematically allocated in each area. All regenerating individuals were inventoried at an inclusion level of less than or equal to $15 \mathrm{~cm}$. The parameters of the horizontal structure, Shannon diversity, Pielou equability and floristic similarity between the studied areas were calculated. The advanced successional forest presented more species, of climax ecological group, however the species with greater number of individuals are pioneers in the two areas. The lower incidence of light in the natural regeneration of the advanced successional forest resulted in a higher density of regeneration species. Both areas had floristic and diversity similarity.
\end{abstract}

Keywords: Atlantic forest; Phytosociology; Subforest.

\footnotetext{
${ }^{1}$ Recebido em 27.08.2017 e aceito para publicação como artigo científico em 23.08.2018.

${ }^{2}$ Engenheiro Florestal, Dr. Professor do Departamento de Ciências Florestais, Universidade Federal de Sergipe. E-mail: <milmarfer@bol.com.br>

${ }^{3}$ Engenheira Florestal, Departamento de Ciências Florestais, Universidade Federal de Sergipe. E-mail: <rochaa_florestal@ $@$ hotmail.com>

${ }^{4}$ Biólogo, Dr. Professor do Departamento de Ecologia, Universidade Federal de Sergipe. E-mail: 〈xannsiqueira@gmail.com>

${ }^{5}$ Estudante de Engenharia Florestal. Departamento de Ciências Florestais, Universidade Federal de Sergipe. E-mail: <icaro.florestall@gmail.com>

${ }^{6}$ Engenheira Florestal, MSc. Doutoranda em Ciências Florestais, Universidade Federal do Espírito Santo. E-mail: <marciarmfe@gmail.com>
} 


\section{Introdução}

As ações antrópicas vêm causando danos irreparáveis aos ecossistemas brasileiros, particularmente à Mata Atlântica, que representa um dos biomas mais ameaçados do planeta. De modo geral, o que ainda resta desse bioma se encontra em fragmentos localizados, geralmente em áreas de difícil acesso ou constituem capoeiras em estágios serais iniciais (XAVIER et al., 2011). Em Sergipe, restam cerca de $8 \%$ da faixa de Mata Atlântica original, representando apenas um terço do estado e, de acordo com alguns estudos, são áreas que permanecem sob constante pressão antrópica (FERREIRA et al., 2011).

Pesquisas sobre a regeneração natural em fragmentos florestais são de suma relevância para $o$ entendimento do funcionamento ecológico desses ecossistemas, pois permitem a inferência sobre a dinâmica de comunidades e populações de espécies arbóreas, que representa uma informação fundamental para o manejo e conservação da floresta. No entanto, compreender o padrão da regeneração de espécies arbóreas é uma tarefa difícil e complexa, pois esta depende da interação entre fatores intrínsecos e extrínsecos, relacionados às características ecológicas e fisiológicas das espécies e às condições ambientais (SANTOS et al., 2015).

A regeneração natural de florestas tropicais segue uma tendência de substituição de espécies pioneiras, intolerantes à sombra e, de crescimento rápido por espécies secundárias tardias ou clímax, de crescimento mais lento. Essas mudanças suscitam transições na dominância de diferentes formas de crescimento vegetal e tipos funcionais. Gramíneas, herbáceas, lianas e arbustos colonizam campos recentemente abandonados, mas se reduzem de forma abundante conforme o dossel da floresta se fecha e limita a disponibilidade de luz (CHAZDON, 2008).

Grande parte desta substituição ocorre durante os estágios de início do povoamento e exclusão das espécies que não toleram sombra, sob o dossel em desenvolvimento de árvores pioneiras longevas, as quais, por sua vez, também são substituídas em estágios tardios de sucessão por espécies lenhosas ombrófila (CHAZDON, 2012). Neste contexto, este trabalho objetivou avaliar a florística, fitossociologia e similaridade florística de espécies do estrato regenerativo de duas áreas de um fragmento de Floresta Ombrófila Semidecidual, em diferentes estágios sucessionais, no município de São Cristóvão, SE.

\section{Material e métodos}

A área de estudo se localiza no Instituto Federal de Educação, Ciência e Tecnologia de Sergipe (IFS), no município de São Cristóvão, Sergipe, sob as coordenadas geográficas de $10^{\circ} 55^{\prime} \mathrm{S}, 37^{\circ} 07^{\prime} \mathrm{W}$, e altitude de $20 \mathrm{~m}$ (Figura 1), com área total de 200 ha de uma Floresta Ombrófila Semidecidual (SERGIPE, 2012).

O período chuvoso é concentrado entre os meses de abril a agosto, com temperaturas elevadas durante todo o ano, com médias anuais em torno de $24{ }^{\circ} \mathrm{C}$ (SERGIPE, 2012). Segundo a classificação de Köppen, predomina o clima tropical com estação seca de verão (As). A área de estudo está inserida na sub-bacia hidrográfica do rio Poxim, que faz parte da bacia do rio Sergipe (SEPLANTEC/SRH, 2004).

Para o estudo, foram selecionadas duas áreas com diferentes níveis de antropização, uma área com maior abertura de dossel (sucessão inicial) e outra com menor abertura de dossel (sucessão avançada). A primeira área corresponde a uma floresta secundária inicial, com maior nível de intensidade luminosa na regeneração natural. Esta área sofreu corte seletivo de espécies florestais para retirada de madeira, há aproximadamente 5 anos. A segunda área corresponde a uma floresta em avançado estágio de sucessão e tem menor abertura de dossel, com um histórico de conservação de aproximadamente 22 anos, sem nenhuma abertura de clareira ou corte de espécies florestais, com um dossel de maior porte. 


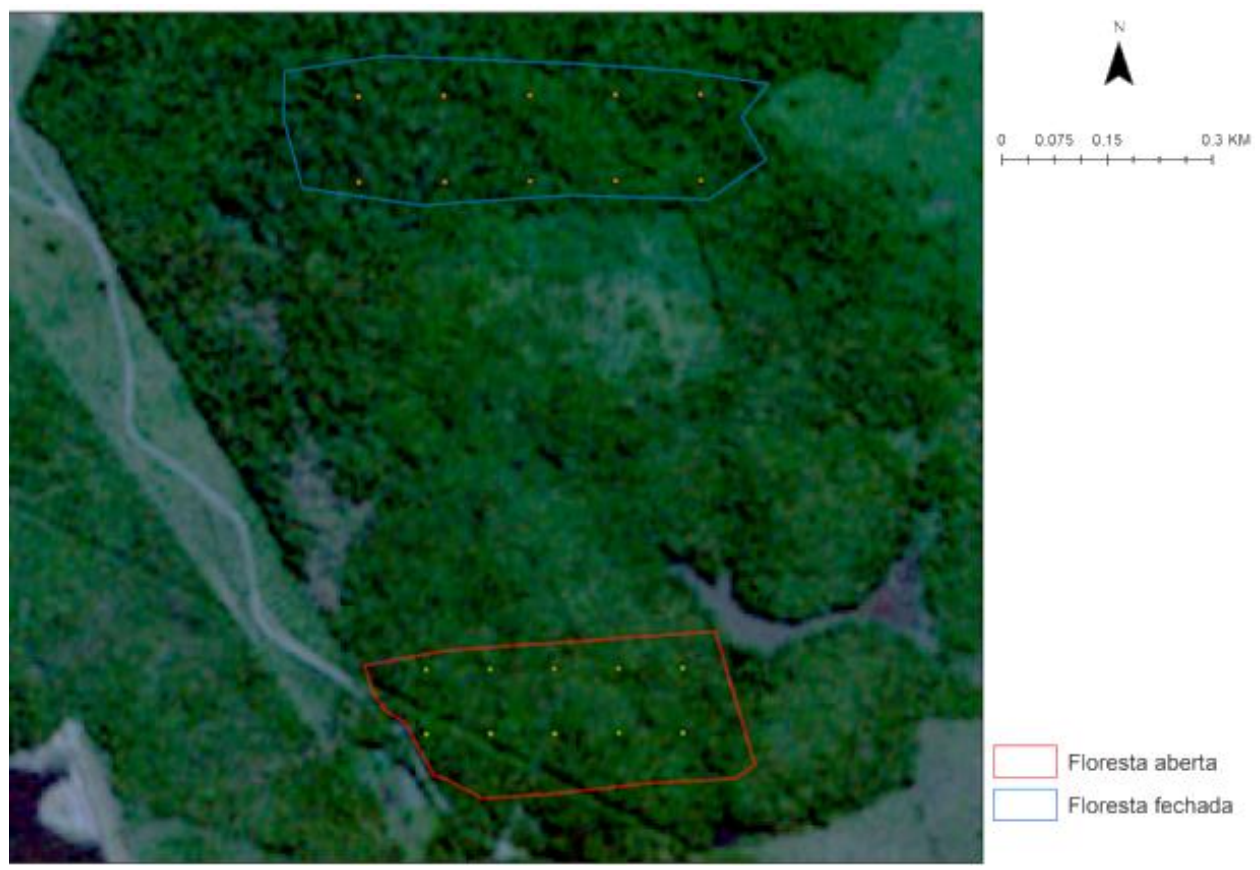

Figura 1 - Localização da área de estudo e croqui das parcelas, São Cristóvão, SE.

Figure 1 - Location of the study area and plots sketch.

De acordo com Martins (2018), a abertura de dossel é um dos principais fatores que influenciam a composição e a estrutura da regeneração natural, sendo fundamental a quantificação da abertura do dossel. Para quantificação da intensidade luminosa, realizou-se a amostragem no centro de cada parcela do levantamento da regeneração natural, com auxílio de um luxímetro, caracterizando área aberta com 47,69\% de intensidade luminosa e a fechada com $16,53 \%$.

O levantamento da regeneração natural foi realizado a partir da demarcação de 10 parcelas de $2 \mathrm{~m}$ x $5 \mathrm{~m}$, dispostas sistematicamente. Estas parcelas foram alocadas dentro de 10 parcelas de $20 \mathrm{~m}$ x $20 \mathrm{~m}$. Foram mensuradas as alturas e os diâmetros dos indivíduos regenerantes em um nível de inclusão menor ou igual a $15 \mathrm{~cm}$ (circunferência ao nível do coleto $\leq 15 \mathrm{~cm}$ ), nas 10 parcelas de $2 \mathrm{~m}$ x $5 \mathrm{~m}$.

A identificação dos indivíduos foi realizada por comparação no Herbário da Universidade Federal de Sergipe (ASE), utilizando-se o sistema de classificação de APG IV (2016). As espécies foram classificadas quanto ao grupo ecológico, de acordo com Budowski (1965), em pioneira, secundária inicial, secundária tardia e clímax.

Foram calculados os parâmetros fitossociológicos da estrutura horizontal: densidade absoluta e relativa, frequência absoluta e relativa, dominância absoluta e relativa e valor de importância (SOUZA e SOARES, 2013). Os resultados de densidade absoluta foram submetidos à análise de variância, pelo teste $\mathrm{F}$ a $1 \%$ de significância, em que as duas áreas foram consideradas como tratamentos e cada parcela uma repetição. Para comparação entre as médias, o teste Tukey foi aplicado com auxílio do programa estatístico $\mathrm{R}$ (R CORE TEAM, 2017).

Para avaliar a similaridade florística da regeneração natural entre as duas áreas, utilizou-se o índice de similaridade de Jaccard (MUELLER DOMBOIS e ELLENBERG, 1974). Na análise da diversidade de espécies foi utilizado o índice de diversidade de Shannon e, para a uniformidade foi empreendida a equabilidade de Pielou, conforme recomendado por Porto et al. (2008). 


\section{Resultados e Discussão}

$\mathrm{Na}$ floresta secundária inicial há 95 indivíduos arbóreos, pertencentes a 16 espécies, compreendidas em 9 famílias botânicas, sendo considerado um baixo número. As famílias que mais se destacaram em número de espécies neste estágio de sucessão são Myrtaceae com 5 espécies, seguida por Moraceae, Sapindaceae e Sapotaceae com 2 espécies cada. Em relação aos grupos ecológicos nesta floresta, o maior percentual é de espécies secundárias iniciais $(37,5 \%)$, seguidas de pioneiras $(25 \%)$ e clímax (25\%), secundárias tardias e não identificadas com $12,5 \%$ cada (Tabela 1 ).

Tabela 1 - Famílias, espécies e grupos ecológicos em floresta secundária inicial, São Cristóvão, SE.

Table 1 - Families, species and ecological groups in initial secondary forest, São Cristóvão, SE state.

\begin{tabular}{|c|c|c|}
\hline Família & Espécie & G.E. \\
\hline Anacardiaceae & Tapirira guianensis Aubl. & pi \\
\hline Annonaceae & Xylopia frutescens Aubl. & pi \\
\hline Bignoniaceae & Handroanthus sp. Mattos & $\mathrm{cl}$ \\
\hline Burseraceae & Protium heptaphyllum (Aubl.) Marchand & pi \\
\hline Lauraceae & Ocotea canaliculata (Rich.) Mez. & pi \\
\hline \multirow[t]{2}{*}{ Moraceae } & Ficus bahiensis C.C. Berg \& Carauta & si \\
\hline & Sorocea hilarii Gaudich. & si \\
\hline \multirow[t]{5}{*}{ Myrtaceae } & Campomanesia aromatica (Aubl.) Griseb. & si \\
\hline & Campomanesia dichotoma (O. Berg) Mattos & st \\
\hline & Myrcia racemosa (O. Berg) Kiaersk. & $\mathrm{cl}$ \\
\hline & Myrcia splendens (Sw.) DC. & pi \\
\hline & Myrcia polyantha $\mathrm{DC}$ & si \\
\hline \multirow[t]{2}{*}{ Sapindaceae } & Cupania impressinervia Acev. - Rodr. & si \\
\hline & Espécie não identificada2 & ni \\
\hline Sapotaceae & Sideroxylonobtusifolium (Roem. \&Schult.) T.D. Penn. & si \\
\hline
\end{tabular}

Na floresta em estágio avançado de sucessão há 139 indivíduos, distribuídos em 17 espécies e 10 famílias botânicas. Esta área apresenta maior percentual de espécies secundárias tardias $(41,17 \%)$. As espécies pioneiras representam 35,29\%, não identificadas $(11,76 \%)$, clímax e secundárias iniciais tiveram o mesmo percentual, com 5,88\% cada (Tabela 2).

O percentual das espécies secundárias tardias e das espécies clímax corresponde a $47,05 \%$ do total na floresta em estágio avançado de sucessão, corroborando o estágio sucessional mais avançado em comparação à floresta secundária inicial. Isto ocorre porque em locais com menor incidência luminosa no piso florestal há maior umidade, favorecendo assim o estabelecimento de espécies florestais mais tolerantes à sombra (ONOFRE et al.,
2010).

A família que apresenta maior número de espécies na floresta em estágio avançado de sucessão é a Myrtaceae, com 6 espécies, seguida de Anacardeaceae e Fabaceae, com 2 espécies cada. A família Myrtaceae predomina nas duas áreas e não há diferença pronunciada em termos de número de famílias botânicas. Estas famílias também se destacam no estudo de Arantes et al. (2012), em reflorestamento (80 meses) e em fragmento preservado. Oliveira et al. (2013a) na avaliação da regeneração natural em nascentes, na mesma região do presente estudo, destacam que a família Myrtaceae também apresenta maior número de espécies, onde demonstram ser comum o alto número de espécies desta família na região. 
Tabela 2 - Famílias, espécies e grupos ecológicos em floresta em estágio avançado de sucessão, São Cristóvão, SE.

Table 2 - Families, species and ecological groups in advanced successional forest, São Cristóvão, SE state.

\begin{tabular}{|c|c|c|}
\hline Família & Espécie & G.E \\
\hline \multirow{2}{*}{ Anacardiaceae } & Mangifera indica $\mathrm{L}$. & pi \\
\hline & Tapirira guianensis Aubl. & pi \\
\hline Annonaceae & Xylopia frutescens Aubl. & pi \\
\hline Bignoneaceae & Handroanthus sp. Mattos & $\mathrm{cl}$ \\
\hline Burseraceae & Protium heptaphyllum (Aubl.) Marchand & pi \\
\hline \multirow{2}{*}{ Fabaceae } & Lonchocarpus sericeus (Poir.) Kunth ex DC. & pi \\
\hline & Mimosa sp. L. & ni \\
\hline \multirow[t]{2}{*}{ Lauraceae } & Ocotea canaliculata (Rich.) Mez & pi \\
\hline & Campomanesia aromatica (Aubl.) Griseb. & st \\
\hline \multirow{5}{*}{ Myrtaceae } & Campomanesia dichotoma (O. Berg) Mattos & st \\
\hline & Myrciaria floribunda (H. West ex Willd.) O. Berg & st \\
\hline & Myrcia polyantha DC. & si \\
\hline & Myrcia racemosa (O. Berg) Kiaersk. & st \\
\hline & Myrcia splendens (Sw.) DC. & pi \\
\hline Polygonaceae & Espécie não identificada1 & ni \\
\hline Salicaceae & Casearia lasiophylla Eichler & st \\
\hline Olacaceae & Schoepfia brasiliensis A. DC. & st \\
\hline
\end{tabular}

Na floresta secundária inicial as espécies $M$. splendens, T. guianensis e $C$. aromatica apresentam maiores VI, que somados correspondem a 30,96\% (Figura 2). No estudo de Santiago et al. (2014), a espécie $M$. splendens apresentou maior VI, semelhante a este estudo. Os autores citam que esta espécie é pioneira, característica esta que favorece o seu desenvolvimento na regeneração natural em ambientes mais abertos e degradados e, também produz frutos atrativos à fauna, aumentando a dispersão de suas sementes.

$\mathrm{Na}$ floresta em estágio avançado de sucessão as espécies com maiores VI são T. guianensis, $P$. heptaphyllum e $O$. canaliculata, que representam 39,29 \% da soma do VI (Figura 2). Oliveira et al. (2013a) observaram altos valores de VI para as espécies T. guianensis e $P$. heptaphyllum na regeneração natural de nascentes na região desse estudo, indicando que estas espécies apresentam uma grande incidência nessa região, independente do grau de conservação e/ou degradação da área. Nesse estudo também se constatou alto VI das espécies $T$. guianensis e $P$. heptaphyllum. Espécies com grande representatividade são fundamentais sendo espécies chave no processo de restabelecimento da vegetação, servindo como fonte de entrada de propágulos e como alimentos para frugívoros e poleiros (FELKER et al., 2018).

A espécie $T$. guianensis tem alto percentual de VI nas duas áreas. A T. guianensis é uma espécie pioneira típica de ambientes abertos e produz frutos que são consumidos pela fauna silvestre, que aumenta sua dispersão e colonização em áreas mais distantes das fontes de propágulos (LORENZI, 2008). Estas características fazem com que a espécie compareça um maior VI na floresta secundária inicial e em floresta em estágio avançado de sucessão.

A Densidade Absoluta (DA) e a Dominância Absoluta (DoA) é de 9.500 ind. $\mathrm{ha}^{-1}$ e 1,134 $\mathrm{m}^{2}$ $\mathrm{ha}^{-1}$, respectivamente na floresta secundária inicial (Tabela 3). As espécies M. splendens, $T$. guianensis e $M$. polyantha têm as maiores Densidades Relativas (DR) e Frequência Relativa (FR). A Ocotea sp. obteve a maior Dominância Relativa (DoR), e as espécies $C$. aromatica, $M$. splendense $T$. guianensis apresentam altos valores de Dominância Relativa (DoR). 


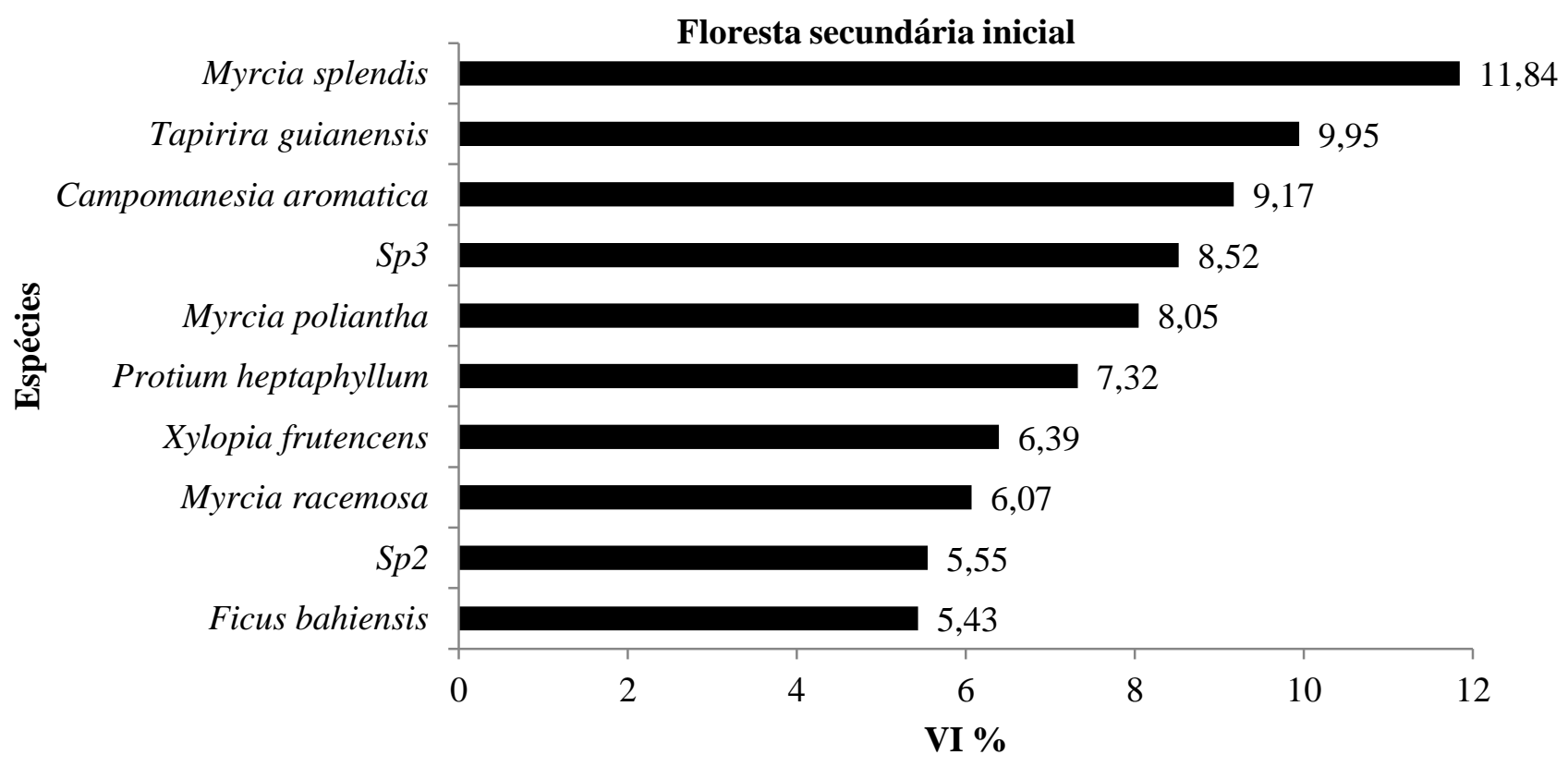

Floresta em estágio avançado de sucessão

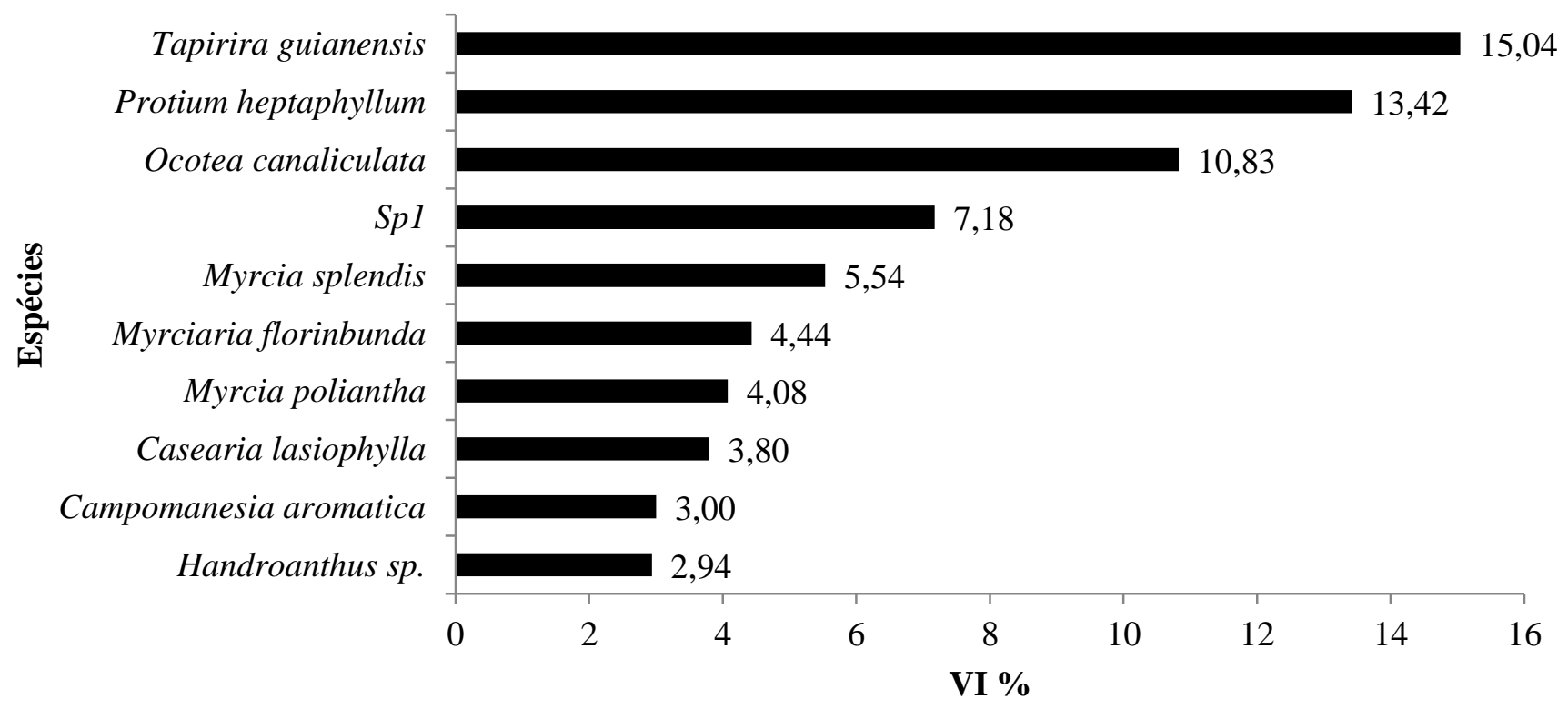

Onde: $\mathrm{Sp}=$ Espécie não identificada

Figura 2 - Valores de Importância (VI) das espécies arbóreas em florestas com diferentes estágios de sucessão, São Cristóvão, SE.

Figure 2 - Values of Importance (VI) of the tree species in different stages of succession, São Cristóvão, SE state. 
Tabela 3 - Estrutura horizontal da regeneração natural em floresta secundária inicial, São Cristóvão, SE.

Table 3 - Horizontal structure of natural regeneration in initial secondary forest, São Cristóvão, SE state.

\begin{tabular}{cccccc}
\hline Espécie & DA & DR & FR & DoA & DoR \\
\hline Myrcia splendens & 1200 & 12,63 & 10,0 & 0,146 & 12,90 \\
Myrcia polyantha & 1000 & 10,53 & 7,5 & 0,069 & 6,11 \\
Tapirira guianensis & 1000 & 10,53 & 10,0 & 0,106 & 9,31 \\
Campomanesia aromatica & 900 & 9,47 & 5,0 & 0,148 & 13,05 \\
Protium heptaphyllum & 800 & 8,42 & 10,0 & 0,040 & 3,55 \\
Xylopia frutescens & 800 & 8,42 & 7,5 & 0,037 & 3,27 \\
Myrcia racemosa & 600 & 6,32 & 5,0 & 0,078 & 6,89 \\
Campomanesia dichotoma & 500 & 5,26 & 5,0 & 0,049 & 4,28 \\
Ficus bahiensis & 500 & 5,26 & 5,0 & 0,068 & 6,04 \\
Espécie não identificada2 & 500 & 5,26 & 5,0 & 0,072 & 6,38 \\
Cupania impressinervia & 400 & 4,21 & 7,5 & 0,041 & 3,62 \\
Ocotea sp. & 400 & 4,21 & 5,0 & 0,185 & 16,34 \\
Sideroxylon obtusifolium & 300 & 3,16 & 7,5 & 0,050 & 4,42 \\
Sorocea hilarii & 300 & 3,16 & 5,0 & 0,018 & 1,59 \\
Ocotea canaliculata & 200 & 2,11 & 2,5 & 0,014 & 1,24 \\
Handroanthus sp. & 100 & 1,05 & 2,5 & 0,011 & 1,01 \\
\hline Total & $\mathbf{9 5 0 0}$ & $\mathbf{1 0 0}$ & $\mathbf{1 0 0}$ & $\mathbf{1 , 1 3 4}$ & $\mathbf{1 0 0}$ \\
\hline
\end{tabular}

DA: Densidade Absoluta (ind. ha $\left.{ }^{-1}\right)$; DR: Densidade Relativa (\%); DoA: Dominância Absoluta $\left(\mathrm{m}^{2}\right.$. ha $\left.{ }^{-1}\right)$; DoR: dominância relativa (\%).

A DA e a DoA da floresta em estágio avançado de sucessão é 11500 ind. ha ${ }^{-1}$ e 1,013 $\mathrm{m}^{2} \mathrm{ha}^{-1}$, respectivamente (Tabela 4). Nesta floresta a DA é alta quando comparado ao estudo de Oliveira et al. (2013b), que observaram uma alta DA (10.853 ind. ha $^{-1}$ ) na regeneração natural de um fragmento de Floresta Ombrófila Densa, em Pernambuco. A Densidade Absoluta (DA) apresentou diferença significativa $(p>0,01)$, sendo a DA na floresta em estágio avançado de sucessão superior à floresta secundária inicial. Em um reflorestamento heterogêneo de mata ciliar, Melo et al. (2015) observaram maior densidade de espécies da regeneração natural, conforme aumenta a interceptação de luz pelo dossel. A DoA apresentou valores próximos entre as áreas.

As espécies T. guianensis, $O$. canaliculata e $P$. heptaphyllum apresentam os maiores valores de DR, FR, DoA e DoR na floresta em estágio avançado de sucessão. A grande expressividade de determinadas espécies, como as citadas anteriormente na regeneração natural, indica que essas são mais adaptadas às condições locais, sendo ideais para uso em projetos de restauração ecológica na região (FELKER et al., 2018). A T. guianensis foi a única espécie que apresentou altos valores de DR, FR, DoA e DoR nas duas áreas.

A espécie $P$. heptaphyllum obteve o maior DoR na floresta em estágio avançado de sucessão, sendo esta espécie com maior taxa de ocupação na regeneração natural. Xavier et al. (2011), em uma Floresta Ombrófila Aberta observaram, em um ambiente mais preservado, um bom estabelecimento de P. heptaphyllum. A alta densidade de $P$. heptaphyllum obtido neste estudo na área mais preservada, também foi observado por Oliveira et al. (2013b), em uma Floresta Ombrófila Densa de Terras Baixas em um fragmento bem preservado.

A similaridade florística, indicada pelo índice de Jacard é de $42,85 \%$, ou seja, as áreas são floristicamente similares e, quando este valor é superior a $40 \%$, pode ser considerada uma alta similaridade. Duas ou mais áreas são consideradas similares em termos de composição florística quando apresentam pelo menos 25\% de espécies comuns (MUELLER DOMBOIS e ELLENBERG, 1974). 
Tabela 4 - Estrutura horizontal da regeneração natural em floresta em estágio avançado de sucessão, São Cristóvão, SE.

Table 4 - Horizontal structure of natural regeneration in advanced successional forest, São Cristóvão, SE state.

\begin{tabular}{|c|c|c|c|c|c|}
\hline Espécie & DA & DR & FR & DoA & DoR \\
\hline Campomanesia aromatica & 200 & 1,74 & 4,08 & 0,050 & 4,91 \\
\hline Campomanesia dichotoma & 200 & 1,74 & 4,08 & 0,036 & 3,54 \\
\hline Casearia lasiophylla & 300 & 2,61 & 6,12 & 0,049 & 4,81 \\
\hline Myrciaria floribunda & 600 & 5,22 & 6,12 & 0,046 & 4,51 \\
\hline Handroanthus sp. & 500 & 4,35 & 4,08 & 0,021 & 2,08 \\
\hline Lonchocarpus sericeus & 400 & 3,48 & 2,04 & 0,006 & 0,63 \\
\hline Mangifera indica & 100 & 0,87 & 2,04 & 0,015 & 1,45 \\
\hline Mimosa sp. & 300 & 2,61 & 2,04 & 0,006 & 0,59 \\
\hline Myrcia polyantha & 400 & 3,48 & 8,16 & 0,029 & 2,82 \\
\hline Myrcia racemosa & 200 & 1,74 & 4,08 & 0,008 & 0,84 \\
\hline Myrcia splendens & 900 & 7,83 & 6,12 & 0,060 & 5,90 \\
\hline Ocotea canaliculata & 1800 & 15,65 & 10,20 & 0.132 & 13,03 \\
\hline Protium heptaphyllum & 1600 & 13,91 & 12,24 & 0,223 & 22,06 \\
\hline Schoepfia brasiliensis & 500 & 4,35 & 2,04 & 0,027 & 2,62 \\
\hline Espécie não identificada1 & 700 & 6,09 & 10,24 & 0,095 & 9,35 \\
\hline Tapirira guianensis & 2500 & 21,74 & 12,24 & 0,204 & 20,13 \\
\hline Xylopia frutescens & 300 & 2,61 & 4,08 & 0,007 & 0,73 \\
\hline Total & 11500 & 100 & 100 & $\mathbf{1 , 0 1 3}$ & 100 \\
\hline
\end{tabular}

DA: Densidade Absoluta (ind. ha ${ }^{-1}$ ); DR: Densidade Relativa (\%); DoA: Dominância Absoluta (m². ha $\left.{ }^{-1}\right)$; DoR: Dominância Relativa (\%).

O valor do índice de diversidade de Shannon $\left(\mathrm{H}^{\prime}\right)$ obtido para a regeneração natural da floresta secundária inicial é 2,63 e, o índice de equabilidade de Pielou de 0,95. Para a floresta em estágio avançado de sucessão, o valor do índice de diversidade de Shannon (H') é de 2,65 e, o índice de equabilidade de Pielou ( $\mathrm{J}$ ') de 0,88 . Estes valores de diversidade de Shannon $\left(\mathrm{H}^{\prime}\right)$ obtidos nas duas áreas foram próximos e podem ser considerados baixos quando comparado ao observado por Aparício et al. (2011), que observaram na regeneração natural um $\mathrm{H}^{\prime}$ de 3,32, em um fragmento de Floresta Ombrófila Densa no estado de Pernambuco. As duas áreas obtiveram uma boa equabilidade de Pielou, na qual indicam certa uniformidade na distribuição do número de indivíduos por espécie (OLIVEIRA et al., 2013b).

Embora as áreas apresentem diferentes aberturas de dossel, estas foram similares quanto à florística e à diversidade de espécies. Em uma Floresta Estacional Semidecidual Aluvial no estado do Paraná, Cruz et al. (2018) quando avaliaram o estrato herbáceo-arbustivo, em duas áreas com diferentes históricos de uso, observaram que não houve diferença de abertura de dossel, no entanto ocorreu diferença na diversidade e composição de espécies. De acordo com os referidos autores, a diferença na idade de recuperação das duas áreas foi determinante na diferenciação da diversidade e composição florística. Nesse estudo, na floresta secundária inicial ocorreu uma retirada seletiva de indivíduos arbóreos há aproximadamente 5 anos, entretanto não houve corte raso da vegetação o que pode ter propiciado uma recuperação mais rápida e tornando-a similar florística e em diversidade a floresta em estágio avançado de sucessão.

\section{Conclusões}

A floresta em estágio avançado de sucessão tem maior número de espécies quando comparada à floresta secundária inicial. Estas espécies pertencem aos grupos ecológicos mais avançados na sucessão, porém as espécies com maior número de indivíduos são pioneiras nas duas áreas.

A menor incidência de luz na regeneração natural da área fechada permitiu uma maior densidade de espécies da regeneração natural comparada à floresta secundária inicial. As duas 
áreas foram similares floristicamente e não se diferenciaram quanto à diversidade e à uniformidade. As espécies T.guianensis e P.heptaphyllum apresentam potencial para restauração de áreas degradadas.

\section{Referências}

APG IV. An update of the Angiosperm Phylogeny Group classification for the orders and families of flowering plants: APG IV. Botanical Journal of the Linnean Society, v.181, p.01-20, 2016.

APARÍCIO, W. C. S. et al. Estrutura da regeneração natural de espécies arbóreas em um fragmento de Mata Atlântica, Pernambuco. Revista Brasileira de Ciências Agrárias, v.6, n. 3, p.483 - 488, 2011.

ARANTES, T. B. et al. Avaliação da regeneração natural como processo de recuperação do entorno de nascente perturbada. Enciclopédia Biosfera, v.8, n.14, p. 1019 1041, 2012.

BUDOWSKI, G. Distribution of tropical American rain forest species in the light of successional progresses. Turrialba, v.15, n.1, p. $40-42,1965$.

CHAZDON, R. L. Chance and determinism in tropical forest succession. In: CARSON, W.; SCHNITZER, S. A. Tropical forest community ecology. Oxford: Wiley - Blackwell Publishing, 2008. p. 384 - 408.

CHAZDON, R. Regeneração de florestas tropicais. Boletim Museu Paraense Emílio Goeldi de Ciências Naturais, v.7, n.1, p. 195 2018, 2012.

CRUZ, M. P.; CAMPOS, J. B.; TOREZAN, J. M. D. Influência da topografia e da abertura de dossel na estrutura do componente herbáceoarbustivo em dois fragmentos florestais na planície de inundação do Alto Rio Paraná.
Ciência Florestal, v. 28, n. 1, p. 191 - 205, 2018.

FELKER, R. M. et al. Regeneração natural em área sob domínio de bambu, no sul do Brasil. Revista de Ciências Agrárias, v. 41, n. 1, p. 8292, 2018.

FERREIRA, R. A. et al. Nascentes da sub-bacia hidrográfica do rio Poxim, estado de Sergipe: da degradação à restauração. Revista Árvore, v.35, n.20, p. 265 - 277, 2011.

LORENZI, H. Árvores brasileiras: Manual de identificação e cultivo de plantas arbóreas nativas do Brasil. 5 ed. São Paulo: Nova Odessa: Instituto Plantarum; 2008. 364p.

MARTINS, S.V. Recuperação de áreas degradadas: Ações em áreas de preservação permanente, voçorocas, taludes rodoviários e de mineração. 4 ed. Viçosa: Aprenda Fácil; 2018. $216 p$.

MELO, A. C. G. et al. Atributos de espécies arbóreas e a facilitação da regeneração natural em plantio heterogêneo de mata ciliar. Scientia Forestalis, v.43, n.106, p. 333 - 344, 2015.

MUELLER - DOMBOIS, D.; ELLENBERG, H. Aims and methods of vegetation ecology. 1 ed. New York: Willey \& Sons; 1974. 66p.

$\mathrm{R}$ CORE TEAM. $\mathrm{R}$ : a language and environment for statistical computing, version 3.3.3. Vienna, Austria: $\mathrm{R}$ Foundation for Statistical Computing, 2017. Disponível em: <https://www.r-project.org/>. Acesso em: 20 fev. 2017.

SANTIAGO, D. S.; FONSECA, C. R.; CARVALHO, F. A. Fitossociologia da regeneração natural de um fragmento urbano de Floresta Estacional Semidecidual (Juiz de Fora, MG). Agrária, v 9, n.1, p. 117 - 123, 2014.

SANTOS, K. F. et al. Regeneração natural do componente arbóreo após a mortalidade de um 
maciço de taquara em um fragmento de Floresta Ombrófila Mista em Lages - SC. Ciência Florestal, v. 25, n.1, p. 107 - 117, 2015.

SERGIPE (Estado). Secretaria de Estado do Meio Ambiente e dos Recursos Hídricos (SEMAR). Florestas em Sergipe: Construindo uma Política Florestal.1 ed. Sergipe: SEMAR, 2012. 360p.

SEPLANTEC- Secretaria de Estado do Planejamento, da Ciência e da Tecnologia. Superintendência de Recursos Hídricos - SRH. Atlas digital sobre recursos hídricos de Sergipe. 1. ed. Aracaju: SRH, 2004. 230p.

SOUZA, A. L.; SOARES, C. P. B. Florestas Nativas: estrutura, dinâmica e manejo.1 ed. Viçosa: Editora UFV; 2013. 322p.

OLIVEIRA, D. G.; FERREIRA, R. A.; MELLO, A. A.; ALMEIDA, E. S. Estrutura diamétrica da vegetação arbustivo - arbórea no entorno de nascentes da bacia hidrográfica do rio Piauitinga, Salgado - SE, Brasil. Biotemas, v.26, n.2, p. 19 - 31, $2013 a$.

OLIVEIRA, L. S. B.; MARANGON, L. C.; FELICIANO, A. L. P.; CARDOSO, M. O.; LIMA, A. S.; ALBUQUERQUE, M. J. B. Fitossociologia da regeneração natural de uma Floresta Ombrófila densa em Moreno, Pernambuco, Brasil. Revista Brasileira de Ciências Agrárias, v.8, n.1, p. 119 - 124, 2013 b.

ONOFRE, F. F.; ENGEL, V. L.; CASSOLA, H. Regeneração natural de espécies da Mata Atlântica em sub-bosque de Eucalyptus saligna Smith, em uma antiga unidade de produção florestal no Parque das Neblinas, Bertioga, SP. Scientia Forestalis, v.38, n.85, p. 39 - 52, 2010.

PORTO, M. L. et al. Comunidades vegetais e fitossociologia: fundamentos para avaliação e manejo de ecossistemas. 1 ed. Porto Alegre: Editora UFRGS, 2008. 210p.

XAVIER, K. R. F. et al. Impactos pós-fogo na regeneração natural em um fragmento de floresta ombrófila aberta no município de Areia, Paraíba, Brasil. Revista Brasileira de Biociências, v.9, n.3, p. 257 - 264, 2011. 